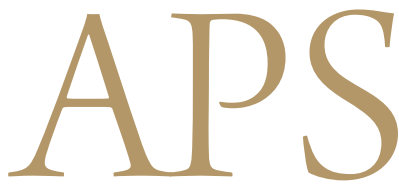

Archives of Plastic Surgery

\title{
Treatment of Fingertip Amputation in Adults by Palmar Pocketing of the Amputated Part
}

\author{
Mi Sun Jung, Young Kook Lim, Yong Taek Hong, Hoon Nam Kim \\ Department of Plastic and Reconstructive Surgery, Daegu Fatima Hospital, Daegu, Korea
}

\begin{abstract}
Background First suggested by Brent in 1979, the pocket principle is an alternative method for patients for whom a microsurgical replantation is not feasible. We report the successful results of a modified palmar pocket method in adults.

Methods Between 2004 and 2008, we treated 10 patients by nonmicrosurgical replantation using palmar pocketing. All patients were adults who sustained a complete fingertip amputation from the tip to lunula in a digits. In all of these patients, the amputation occurred due to a crush or avulsion-type injury, and a microsurgical replantation was not feasible. We used the palmar pocketing method following a composite graft in these patients and prepared the pocket in the subcutaneous layer of the ipsilateral palm.

Results Of a total of 10 cases, nine had complete survival of the replantation and one had $20 \%$ partial necrosis. All of the cases were managed to conserve the fingernails, which led to acceptable cosmetic results.

Conclusions A composite graft and palmar pocketing in adult cases of fingertip injury constitute a simple, reliable operation for digital amputation extending from the tip to the lunula. These methods had satisfactory results.
\end{abstract}

Keywords Amputation / Finger / Replantation

Correspondence: Yong Taek Hong Department of Plastic and

Reconstructive Surgery, Daegu Fatima Hospital, 99 Ayang-ro, Dong-gu,

Daegu 701-724, Korea

Tel: $+82-53-940-7340$

Fax: +82-53-954-7344

E-mail: plastika@naver.com

No potential conflict of interest relevant to this article was reported.

Received: 9 Feb 2012 • Revised: 6 May 2012 • Accepted: 7 May 2012

pISSN: 2234-6163 • elSSN: 2234-6171 • http://dx.doi.org/10.5999/aps.2012.39.4.404 • Arch Plast Surg 2012;39:404-410

\section{INTRODUCTION}

The distal portion of the finger is exposed to a high risk of amputation. As expected, patients with finger amputation are eager to restore the length and functions of their damaged fingers to the original state. Because the artery of a fingertip has a small diameter and several branches, however, the distal portion has a low replantation success rate. In addition, replantation can be difficult without a sufficient blood supply for the survival of the tissue of an amputated distal portion of a finger or if the site of the amputation has been severely crushed or the amputation was due to an avulsion injury $[1,2]$. The general methods for reconstructing a finger with an amputated distal portion include secondary intention, microreplantation, revision amputation, local flap, skin graft, and composite grafting [1-11]. Microreplantation is beneficial, if there is an injury to Tamai zone I or there is a crushing injury or an avulsion injury to the fingertip in Tamai zone II, because its use is restricted in the replantation (Fig. 1) [2]. In addition, a revision amputation greatly shortens the length of the amputated finger, which might also cause a hook-nail deformity [2]. A local flap is beneficial, however, for retaining the length of the finger while preserving the vital tissue that should be protected (bone, ligament, and nerve) and reconstructing the amputated portion of the finger to the

Copyright $\odot 2012$ The Korean Society of Plastic and Reconstructive Surgeons

This is an Open Access article distributed under the terms of the Creative Commons Attribution Non-Commercial License (http://creativecommons.org/

licenses/by-nc/3.0/) which permits unrestricted non-commercial use, distribution, and reproduction in any medium, provided the original work is properly cited.

www.e-aps.or 
donor tissue whose characteristics are similar to the normal tissue of the fingertip. However, this method has a disadvantage, however, in that necrosis might occur at the surgical sites when a higher tension is exerted on the suture; the higher tension impairs the blood circulation of the finger, which can lead to ischemia and tissue loss. Due to the deformity of the fingertip, this method may also cause a malposition of the nail bed and a hook-nail deformity. Therefore, the surgical sites should be free from tension [4]. Besides, composite grafting has a high success rate and produces good results in treating the amputations of non-replantable fingertips in pediatric patients, but it has also been reported, however, that its success rate is as low as approximately $20 \%$ in adults $[11,12]$. In cases of injuries that occur too far distal on a finger for microsurgery, however, there are options to avoid shortening the digit. These options include composite grafting and the replacement of dressing on the stump, which would be essential for the finger to heal with

\section{Fig. 1. Territories of the digits and hand}

The borderline between the hand and digits is placed at the superficial palmar arterial arch, and each digit is divided into 5 zones (I to $\mathrm{V}$ ), which are defined according to the anatomy of the blood vessels and flexor tendons, with special reference to the replantation technique. Zone I, distal end to lunula; zone II, distal interphalangeal joint to lunula (From Tamai, with permission from The American Society for Surgery of the Hand [2]).
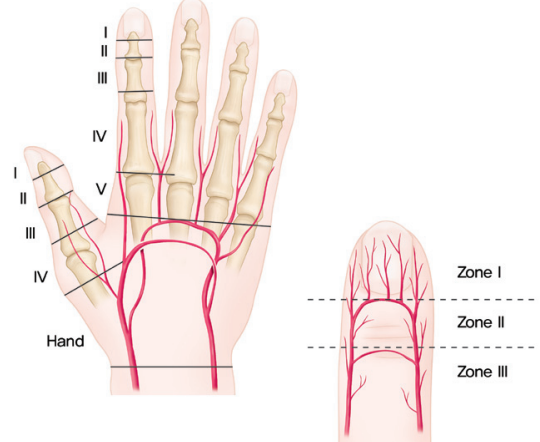

a secondary intention. Secondary intention involves healing of a finger that will have less than a normal function and may not be aesthetically pleasing. Therefore, despite a lower success rate and a narrow scope of application, composite grafting remains a useful surgical modality for reconstructing an amputated finger, if the diameter of the blood vessels distributed in the fingertip is smaller than $0.5 \mathrm{~mm}$. Anastomosis cannot be easily achieved if the distal portion of a finger was amputated due to a crushing injury or an avulsion injury. In addition, composite grafting is particularly useful for patients who want their amputated fingers restored to the original functional and aesthetic status.

Many studies have reported that the success rate of the composite grafting procedure has improved. Brent [13] was the first to introduce the subcutaneous pocketing method. With the de-epithelization of the amputated fingertip, its re-attachment to the stump, and its placement in a subcutaneous pocket, this author raised the status of the nutrient supply. Thus, this author reported good outcomes from both functional and aesthetic perspectives. In recent years, Arata et al. [14], a scholar from Japan, has reported that successful treatment outcomes were obtained using palmar pocketing at the subcutaneous pocket site. To date, many authors have used the contralateral axillary region and abdomen as a pocket site. However, no Korean authors have reported attempting to use the palmar pocket method. Arata et al. [14] performed the palmar pocket method in a wide range of patients extending from pediatric to adult patients. In adults, however, the composite graft is not generally used to reconstruct the non-replantable amputated fingertip. There are a few published studies on composite graft survival of non-replantable amputated fingertips in adults and alternative methods to enhance graft survival [8-10]. We used a palmar pocket method following the composite graft with fingertip amputation during a period ranging from February 2004 to December 2008 in 10 adult patients. We performed a retrospective analysis of these patients. Here, we report our surgical methods and their treatment outcomes.

\section{Table 1. Summary of cases}

\begin{tabular}{|ccccccc|}
\hline Case & Age/Sex & $\begin{array}{c}\text { Warm ischemic } \\
\text { time (hr) }\end{array}$ & Types of injury & Injury site & Level & Survival \\
\hline 1 & $32 / \mathrm{F}$ & 1 & Avulsion & Right long finger & Zone I & Complete \\
2 & $47 / \mathrm{M}$ & 2.5 & Avulsion & Right little finger & Zone I & Complete \\
3 & $34 / \mathrm{M}$ & 2 & Avulsion & Right long finger & Zone I & Complete \\
4 & $41 / \mathrm{M}$ & 2.5 & Avulsion & Right ring finger & Zone II & Complete \\
5 & $32 / \mathrm{M}$ & 1 & Avulsion & Left index finger & Zone I & Complete \\
6 & $30 / \mathrm{F}$ & 1.5 & Crushing & Left ring finger & Zone I & Complete \\
7 & $38 / \mathrm{M}$ & 1 & Avulsion & Right index finger & Zone I & Complete \\
8 & $44 / \mathrm{M}$ & 2.5 & Crushing & Right long finger & Zone II & Complete \\
9 & $28 / \mathrm{M}$ & 1.5 & Avulsion & Right ring finger & Zone I & Complete \\
10 & $36 / \mathrm{M}$ & 2 & Avulsion & Right long finger & Zone I & \\
\hline
\end{tabular}




\section{METHODS}

We conducted the current retrospective study in 10 adult patients with fingertip amputation due to a severe crushing injury in Tamai zone I or Tamai zone II during a period ranging from February of 2004 to December of 2008, for whom a micro-replantation could not be performed (Table 1). There were eight cases of amputation in Tamai zone I and two cases in Tamai zone II. The functional outcomes were subjectively measured with two-point discrimination and the aesthetic outcomes were evaluated using a patient self-reporting questionnaire, both of which were performed in postoperative month 6 .

\section{Sex and age distribution}

Our clinical series of patients consisted of eight men and two women, whose mean age was 36.2 years (range, 28 to 47 years).

\section{Causes, types of injury, occupation, and distribution}

Causes of injury include eight cases $(80 \%)$ of injury due to a press machine and two cases (20\%) of crushing injury due to a door. Types of injury include seven cases (70\%) of crushing injury and three cases (30\%) of avulsion injury. Of the ten patients, nine were workers at a steel company and the remaining one worked at a restaurant. All of these patients lived in Pohang city, which is known for its iron and steel industry.

\section{Methods of anesthesia}

All of the 10 patients underwent brachial plexus block anesthesia.

\section{Surgical methods}

Under the brachial plexus block, the usual preparation and draping were aseptically performed. This was followed by the application of a pneumatic tourniquet in the upper arm ipsilateral to the amputation site. Following the elevation of a pneumatic tourniquet up to $250 \mathrm{~mm} \mathrm{Hg}$, the amputated fingertip was massively irrigated with saline. If the tissue destruction was severe due to a crushing injury, marginal debridement was performed to remove some part of the necrotized tissue. In these cases, the nail was removed and the amputated fingertip was deepithelialized down to the mid-dermal layer by using a No. 10 scalpel blade. If there was a concurrent presence of a fracture of the distal phalanx, the fixation was done using a Kirschner wire. With the minimization of the external exposure of the Kirschner wire, the amputated site was re-planted using 5-0 Nylon. In addition, the composite graft was performed with the restoration of the nails using 6-0 Vicryl. The pocket was prepared on the ipsilateral palm where the finger pulp was placed in contact with as much surface of the pocket bed as possible and the finger had a contact following the flexion after the composite graft. A transverse incision of about $2 \mathrm{~cm}$ was made in the ipsilateral palm and the middle or deep subcutaneous layer was undermined to make a pocket.

Thus, following the creation of a pocket, the finger was fixed to the subcutaneous tissue after the composite graft until the distal interphalangeal (DIP) joint was reached in the palm using 4-0 Nylon. This was followed by dressing using a short arm Yogips splint. Then, light dressing was performed with the wrist and proximal interphalangeal (PIP), joint flexed and a massive compression dressing was avoided. The fingertip was carefully isolated between postoperative days 16 and 18, which was followed by suturing using 4-0 Nylon. The isolated finger was immediately subjected to active and passive joint movement and this was also followed by dressing.

\section{RESULTS}

Of a total of ten patients who underwent the composite graft and palmar pocketing, nine had successful treatment outcomes. Of these, one patient had $20 \%$ partial necrosis. In all the patients with fingertip amputation, the dressing was performed between postoperative day 16 and 18 . The epidermis and nail at the operated sites were partially reconstructed. The functional outcomes were evaluated based on the range of sensation and joint movement. At the 6-month follow-up, the recovery of sensation was subjectively evaluated using two-point discrimination in all of the patients. This showed that nine of ten patients had a mean for two-point discrimination of $<6.5 \mathrm{~mm}$ (Table 2). The motor function was also evaluated based on the active range of motion in the metacarpophalangeal, PIP, and DIP joints. The mean ranges of motion of these joints were $88^{\circ}, 105^{\circ}$, and $72^{\circ}$, respectively. The aesthetic outcomes were evaluated using a patient self-reporting questionnaire, which showed that nine patients were very satisfied and the remaining one was somewhat satisfied about the pigmentation, flat pulp, atrophy, and hypertrophic scar (Table 3).

In the subcutaneous tissue of the palm, the treatment outcomes were evaluated based on the active and passive joint movement during a 1-month period immediately after the isolation of the amputated finger. This showed that the treatment outcomes

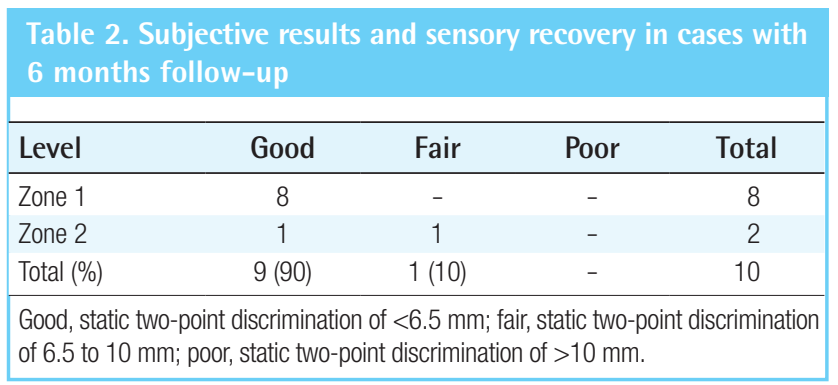


were satisfactory from both functional and aesthetic perspectives. There were no such cases as severe flexion contracture, hook-nail deformity, inflammation, or a depocketed finger. In addition, all of the patients were satisfied with the residual scars although slight hyperpigmentation was left. A tender tip was noted in a 30-year-old woman, who was still found to be able to normally use the injured digit in daily living. Overall, all of our clinical series of patients were satisfied with the cosmetic appearance and function of the replanted fingers.

\section{Table 3. Self-reported questionnaire and its results}

\begin{tabular}{|lc|}
\hline \multicolumn{1}{|c}{ Questionnaire: how satisfied are you with the aesthetic result } & Results \\
\hline Good (very satisfied): less prominent about pigmentation, flat pulp, atrophy and hypertrophic scar & 9 \\
Fair (slightly satisfied): some noticeable about pigmentation, flat pulp, atrophy and hypertrophic scar & 1 \\
Poor (completely unsatisfied): prominent about pigmentation, flat pulp, atrophy and hypertrophic scar & 0 \\
Total & 10 \\
\hline
\end{tabular}

\section{Fig. 2. Case}

(A) Preoperative dorsal view, complete amputation of the fingertip of the right long finger by a pressure machine (Tamai zone I) in a 36-yearold female patient. (B) Preoperative palmar view. (C) Intraoperative dorsal view, deepithelization with a composite graft. (D) Intraoperative palmar view. (E) Immediate postoperative view, pocketing of the right hand. (F) Dorsal view after the depocketing of the finger. (G) Dorsal view after the division on postoperative month 2. $(\mathrm{H})$ Dorsal view on postoperative month 6. (I) Palmar view on postoperative month 6. (J) Grasping seen on postoperative month 6 .
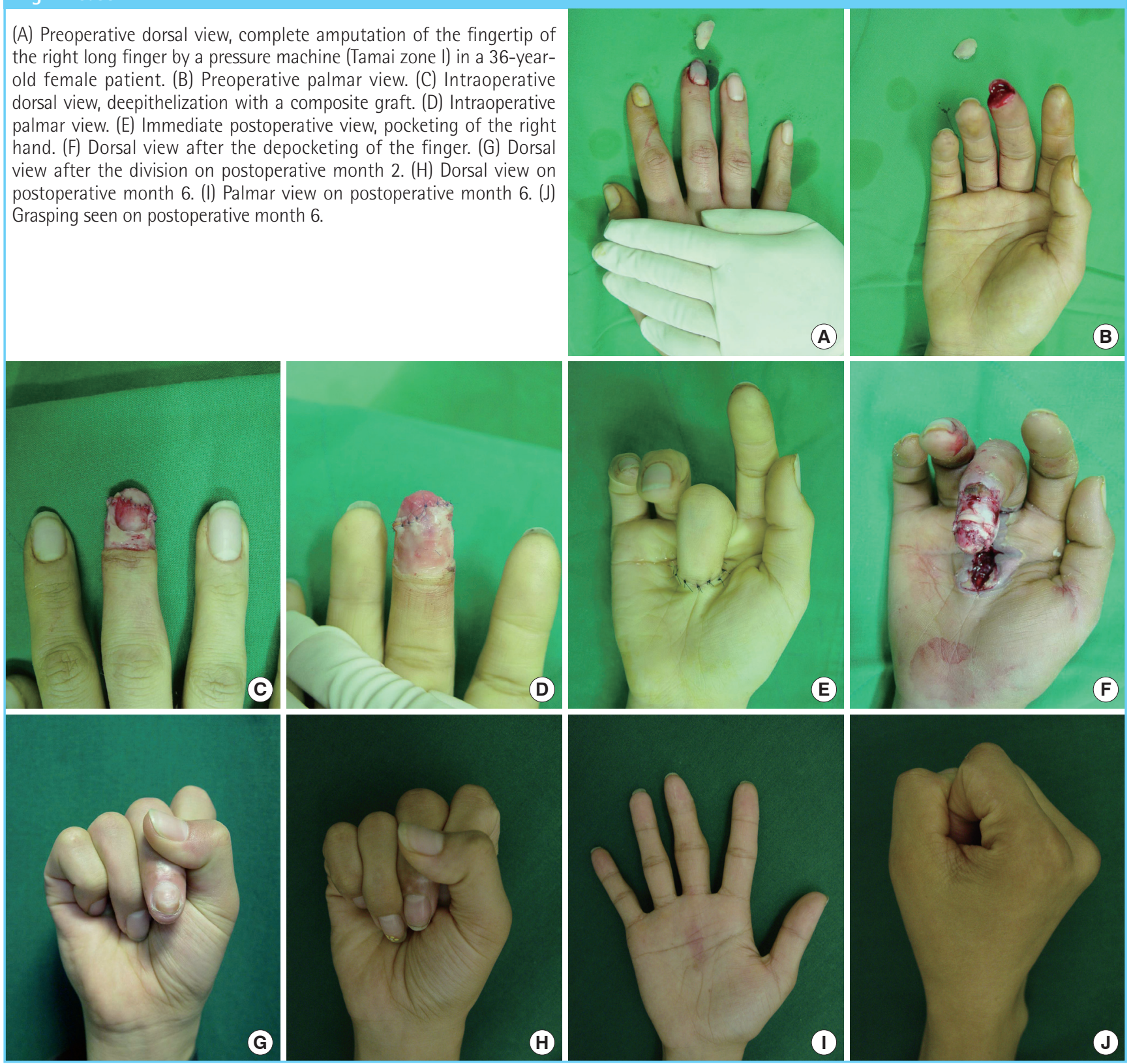


\section{Case description}

In a case representative of our experience in this series, a 32-yearold woman visited us with a chief complaint of an injury to the right long finger that the patient had sustained in a press machine at a steel press factory. The patient had experienced a complete amputation of Tamai zone I and the amputated part and amputation stump had a relatively clean status (Fig. 2). Although this patient was injured at Tamai zone I, we could not perform a microanastomosis and composite graft because the rate of treatment success has been reported to be relatively low. Because the current case was a non-smoking young woman, the palmar pocketing method with a composite graft was performed to resolve cosmetic problems. The patient had the amputated finger isolated three weeks postoperatively. This was followed by conservative treatment for another approximately three weeks. There was a mild pigmentation in the finger, but this was almost unnoticeable. Overall, the treatment outcomes were satisfactory in our series.

\section{DISCUSSION}

In patients with fingertip amputation, treatment goals are to achieve good functional and aesthetic outcomes. In these patients, a microanastomosis under microscopy is an essential, fundamental surgical modality, but microsurgical replantation is not always feasible for the reconstruction of a traumatic fingertip amputation for several reasons. Common situations that prevent the microsurgical replantation of a fingertip amputation [1,9] include the following: 1) a lack of appropriate vessels for anastomosis because of the distal level of the amputation including that in Tamai zone I in particular, 2) severe soft tissue crushing injury, 3) a high risk of prolonged surgery in the elderly, 4) unavailability of microscopic equipment.

In association with this, some authors have explained that a replantation cannot be performed for injuries to Tamai zone I and II not only because the blood vessels have a smaller diameter and several branches but also because there are no veins of sufficient size for anastomosis $[1,2]$.

The survival of a composite graft in the amputated fingertip is dependent on the absorption of the body fluid in the amputated stump as well as the vascular in growth and revascularization of the graft. McFarlane and Wermuth [15] reported that the ischemia and necrosis of the a composite graft could be diminished using a hyperbaric oxygen therapy in with a pedicle flap as well as the severely damaged extremity. In addition, Hirase [11] reported that on the method of cooling the entire recipient site until neovascularization of the graft was developed. The successful outcomes of composite grafting in the reconstruction of the fingertips have been well documented. To date, however, good outcomes of composite grafting of fingertip amputations have mainly been reported from for children. In addition, it remains unclear whether this method would also be appropriate for adults [12]. It is generally known that the survival of a composite graft cannot be expected in the fingertip amputation in the Tamai zone I and II, particularly in adults $[3,11,12]$. It has therefore been proposed that the amputated fingertip should be placed in the subcutaneous tissue for 2 to 3 weeks to improve the survival of the replantation of the amputated fingertip using the a composite graft. Thus, attempts have been made to promote the revascularization of the amputated fingertip. To improve the survival of the composite graft, the vascular bed and the available contact surface should be increased. This would be one of the essential measures for the survival of the composite graft for the amputated finger. Rose et al. [8] and Uysal et al. [9] described the "cap" technique for enhancing composite graft survival by increasing the contact area between the distal amputated fingertip and the amputated stump. Several reports have described the pocket method $[3,13,14,16-20]$. The replantation of the amputated finger using subcutaneous pocketing was first proposed by Gilles in 1940. Gilles removed the skin at the amputated fingertip and then implanted it into the recipient site using a tubed pocket. This surgical method was further developed by Gordon in 1944, Wilflingseder in 1952, and Gillies and Reid [21] in 1955. However, their methods have been applied to all kinds of amputated fingers without respect for the level of the amputated finger. Thereafter, Mladick et al. [16] reported that good treatment outcomes were obtained by applying subcutaneous pocketing to the amputated ear. With the modification of the Gillies technique, Brent [13] attempted a replantation of the amputated finger by performing deepithelization of the amputated finger between the lunula and the DIP joint and embedding it in a subcutaneous pocket. Of four patients, two had experienced a complete amputation of the fingertip and these patients presented with depocketing 11 and 21 days later, respectively, after the pocketing following the replantation. In these patients, dryness occurred without re-epithelialization. In another two patients who had experienced incomplete amputation of the fingertip, depocketing occurred 20 days later. These other two patients achieved complete survival following a split thickness skin graft; Brent thereby reported a success rate of 50\%.

Therefore, in an effort to raise the survival rate of the composite graft and subcutaneous pocketing, Kim et al. [17] attempted direct contact of the deepithelialized finger pulp to the deep abdominal fascia rather than the subcutaneous adipose layer. Thus, Kim et al. [17] achieved complete survival at a rate of 58\%. Brent [13] used the contralateral chest wall as a pocket site. Lee et al. [3] used the abdomen and the inguinal region as a pocket site. 
Using the above body areas as a pocket site may also cause joint stiffness and discomfort due to the long-term immobilization of the wrist and elbow and shoulder joints. This might also lead to a concern that a pocketed finger might be incidentally pulled and this might lead to a depocketing in many patients. To resolve these problems, Arata et al. [14] used the ipsilateral palm as a pocket site in 2001. Thus, this author achieved a complete survival in 13 of 16 cases of the fingertip amputation between the tip and the lunula. Besides, this author also reported that there were only three cases of necrosis in a small area of the tip. In the use of the ipsilateral palm as a pocket site, a smaller area of the joint is involved. In addition, the pocket site is comfortable, safe, and less rigid and it helps pediatric patients to maintain their posture during the pocketing period. Moreover, the palmar pocket improves the vascular bed and increases the surface area for the vascular contact. Thus, it eventually raises the survival rate of the finger after the composite graft.

In 2004, Muneuchi et al. [18] examined the level of the fingertip amputation and the scope of application of the Brent technique. According to this author, a micro-replantation could not be performed for seven fingers because the proximal or cross amputation occurred in the lunula where a crushing or avulsion injury occurred. Of these fingers, only one finger achieved a complete recovery. Thus, the above author reported that the level and type of the fingertip amputation are closely associated with the prognosis.

In Korea, Baek et al. [19] and Lee et al. [20] have published reports about the subcutaneous pocket method. According to Baek, who used the axilla, inguinal area, and contralateral chest wall as pocket sites, the success rate was $60 \%$. Baek reported that the degree of the effective immobilization and the prevention of inflammation and hematoma would be essential factors for successful survival. Thereafter, Lee used hyperbaric oxygen therapy in combination with the subcutaneous pocketing method in eight cases of finger amputation between the DIP joint and lunula in an effort to raise the survival rate of the composite graft. According to this author, complete survival was achieved in five of eight cases of complete amputation, only partial necrosis was present in the pulp in two cases and complete necrosis was present in the remaining one case. As described here, good treatment outcomes were obtained.

In our clinical series of patients with fingertip amputation during a period ranging from 2004 to 2008 , we successfully achieved survival without notable necrosis in nine of ten cases of complete amputation with one case of small partial necrosis. We have provided a proper, direct contact between the composite graft and the palmar pocket. Furthermore, we have also prevented the occurrence of hematoma in a subcutaneous pocket using strict hemostasis and light compression dressing. Furthermore, we have minimized the injury to the contact surface using a 3-week rigid fixation. Thus, attempts were made to prevent injury to the pocket site. The functional recovery was evaluated using a static two-point discrimination test. No patients had postoperative numbness, and one patient had a tender tip. However, no patients had problems with normal daily activities. The aesthetic results were evaluated using a patient self-reporting questionnaire, which indicated that nine of ten were very satisfied and one was somewhat satisfied. Overall, all of our clinical series of patients were satisfied with the postoperative outcomes. In patients with a fingertip amputation, a composite graft combined with palmar pocketing is a relatively simple modality. This surgical modality can also be applied to patients for whom a microsurgical replantation or a local flap cannot be performed because of a crushing or avulsion injury. In addition, the modality is also useful in not only raising the survival rate but also retaining the length of the nail and finger following the composite graft in adults aged six years or older. It might therefore be considered a useful modality where satisfactory treatment outcomes could be obtained from both functional and aesthetic perspectives. The use of the palmar pocket method increases the surface area for vascular contact. Because strict hemostasis and postoperative care prevent the occurrence of hematoma, the survival rate of the composite graft would be higher compared with that of the contralateral chest wall and lower abdomen as a pocket site. Besides, it reduces a concern that it causes joint stiffness and pulls the pocketed finger, which can then lead to depocketing. Thus, it enhances the degree of patient satisfaction with the treatment outcomes.

The limitations of the current study are that our results cannot be generalized due to the small sample size and relatively short (six month) follow-up period. Further long-term follow-up studies are warranted to evaluate the recovery of sensation and joint movement as well as the possibility of volume loss in the fingertip.

\section{REFERENCES}

1. Yamano Y. Replantation of the amputated distal part of the fingers. J Hand Surg Am 1985; 10:211-8.

2. Tamai S. Twenty years' experience of limb replantation: review of 293 upper extremity replants. J Hand Surg Am 1982;7:549-56.

3. Lee PK, Ahn ST, Lim P. Replantation of fingertip amputation by using the pocket principle in adults. Plast Reconstr Surg 1999;103:1428-35.

4. Grad JB, Beasley RW. Fingertip reconstruction. Hand Clin 
1985; 1:667-76.

5. Elsahy NI. When to replant a fingertip after its complete amputation. Plast Reconstr Surg 1977;60:14-21.

6. Elsahy NI. Replantation of a completely amputated distal segment of a thumb: case report. Plast Reconstr Surg 1977; 59:579-81.

7. Heistein JB, Cook PA. Factors affecting composite graft survival in digital tip amputations. Ann Plast Surg 2003;50:299303.

8. Rose EH, Norris MS, Kowalski TA, et al. The "cap" technique: nonmicrosurgical reattachment of fingertip amputations. J Hand Surg Am 1989; 14:513-8.

9. Uysal A, Kankaya Y, Ulusoy MG, et al. An alternative technique for microsurgically unreplantable fingertip amputations. Ann Plast Surg 2006;57:545-51.

10. Chen SY, Wang CH, Fu JP, et al. Composite grafting for traumatic fingertip amputation in adults: technique reinforcement and experience in 31 digits. J Trauma 2011;70:148-53.

11. Hirase Y. Postoperative cooling enhances composite graft survival in nasal-alar and fingertip reconstruction. Br J Plast Surg 1993;46:707-11.

12. Moiemen NS, Elliot D. Composite graft replacement of digital tips. 2. A study in children. J Hand Surg Br 1997;22: 346-52.

13. Brent B. Replantation of amputated distal phalangeal parts of fingers without vascular anastomoses, using subcutane- ous pockets. Plast Reconstr Surg 1979;63:1-8.

14. Arata J, Ishikawa K, Soeda $H$, et al. The palmar pocket method: an adjunct to the management of zone I and II fingertip amputations. J Hand Surg Am 2001;26:945-50.

15. McFarlane RM, Wermuth RE. The use of hyperbaric oxygen to prevent necrosis in experimental pedicle flaps and composite skin grafts. Plast Reconstr Surg 1966;37:422-30.

16. Mladick RA, Horton CE, Adamson JE, et al. The pocket principle: a new technique for the reattachment of a severed ear part. Plast Reconstr Surg 1971;48:219-23.

17. Kim KS, Eo SR, Kim DY, et al. A new strategy of fingertip reattachment: sequential use of microsurgical technique and pocketing of composite graft. Plast Reconstr Surg 2001;107: 73-9.

18. Muneuchi G, Kurokawa M, Igawa K, et al. Nonmicrosurgical replantation using a subcutaneous pocket for salvage of the amputated fingertip. J Hand Surg Am 2005;30:562-5.

19. Baek SK, Lee CJ, Han SH. Replantation of amputated distal phalangeal parts of fingers by using composite graft and subcutaneous pocketing. J Korean Soc Plast Reconstr Surg 1991;18:969-75.

20. Lee HB, Chung IH, Tark KC, et al. Replantation of amputated distal phalangeal parts of finger using subcutaneous pockets. J Korean Soc Plast Reconstr Surg 1995;22:376-82.

21. Gillies H, Reid DA. Autograft of the amputated digit. Br J Plast Surg 1955;7:338-42. 


\section{Discussion}

\section{Reconstruction of Fingertip Amputation: Necrosis Is Expected}

Sae Hwi Ki

Department of Plastic and Reconstructive Surgery, Kwang-Myung Sung-Ae General Hospital, Gwangmyeong, Korea

The first case of replantation of the thumb was reported by Komatsu and Tamai in 1968 [1]. Recently, the quality of reconstruction and replantation in fingertip amputation from the distal unula have been improved. Even microsurgical replantation of amputated children's fingers became possible with a fine microsurgical technique.

However, the fingertip amputations from severe avulsion or crushing injury may prove challenging, especially in such cases where the transected blood vessel cannot be identified. When the necrosis of the amputation stump by either spasm or thrombosis is suspected after microreplantation, the surgeon can perform several surgical or nonsurgical procedures to improve the survival rate of the amputation stump.

In the past, the subcutaneous pocket method in the areas of the groin, axilla, or chest was used for the impossible microsurgical replantation of the finger amputation. In 2001, Arata et al. [2] reported using the palmar subcutaneous pocket for fingertip replantation with a composite graft. However, whether the subcutaneous pocketing method should be the first choice remains questionable because the requisite 2 to 3 week fixation period could result in joint stiffness and prolonged rehabilitation.

There are a number of factors related to the success rate and complications in replantation and reconstruction of a fingertip amputation. These factors include patient age, sex, occupation, hand dominance, pre-existing medical condition, vasculopathy, tobacco use, amputation level and site, patient motivation and cooperation, and surgical method.

In cases of microsurgically impossible replantation of a fingertip amputation, composite graft with either induced limited hypothermic therapy or the wet dressing technique and hyperbaric oxygen therapy may allow graft survival in pediatric patients without joint stiffness [3].

A 2nd toe pulp free flap or other free flap can be very effective for sensory recovery and durability of the fingertip in reconstruction of a fingertip defect with useless amputated segments.
However, the increased microsurgical technical requirements and hospital stay for the patient are drawbacks [4].

Local flaps such as a volar V-Y advancement flap or a lateral $\mathrm{V}-\mathrm{Y}$ advancement flap could allow for a short recovery interval and preserve sensory innervation, especially in cases of either dorsally oblique or transverse complete amputation. Digital artery perforator flaps, such as a propeller flap, are also good alterative choices. If thrombosis and spasm threaten replantation survival after microreplantation, sequential use of a microsurgical technique and pocketing of composite graft method described by Kim et al. [5] in 2001 is a valid alternative management technique in these cases.

In conclusion, microsurgical replantation of fingertip amputations at the level distal to the lunula can prove challenging, especially if microvascular anastomosis is in question. For each therapeutic option discussed above, the factors which effect the outcome and complication rate should be guidelines deciding the indication.

\section{REFERENCES}

1. Komatsu S, Tamai S. Successful replantation of a completely cut-off thumb: case report. Plast Reconstr Surg 1968;42: 374-7.

2. Arata J, Ishikawa K, Soeda $\mathrm{H}$, et al. The palmar pocket method: an adjunct to the management of zone I and II fingertip amputations. J Hand Surg Am 2001;26:945-50.

3. Son DG, Chu HJ, Yeo HJ, et al. Fingertip composite grafting managed with moist-exposed dressing. J Korean Soc Surg Hand 2012;17:9-15.

4. Lee DC, Kim JS, Ki SH, et al. Partial second toe pulp free flap for fingertip reconstruction. Plast Reconstr Surg 2008; 121:899-907.

5. Kim KS, Eo SR, Kim DY, et al. A new strategy of fingertip reattachment: sequential use of microsurgical technique and pocketing of composite graft. Plast Reconstr Surg 2001; 107:73-9.

Correspondence: Sae Hwi Ki

Department of Plastic and Reconstructive Surgery, Kwang-Myung Sung-Ae General Hospital,

36 Digital-ro, Gwangmyeong 423-711, Korea

Tel: +82-2-2680-7238, Fax: +82-2-2615-7218, E-mail: mdki1967@yahoo.com

No potential conflict of interest relevant to this article was reported.

Received: 19 Jun 2012 • Revised: 20 Jun 2012 • Accepted: 21 Jun 2012

pISSN: 2234-6163・ elSSN: 2234-6171

http://dx.doi.org/10.5999/aps.2012.39.4.411 • Arch Plast Surg 2012;39:411

Copyright $(\odot) 2012$ The Korean Society of Plastic and Reconstructive Surgeons

This is an Open Access article distributed under the terms of the Creative Commons Attribution Non-Commercial License (http://creativecommons.org/

licenses/by-nc/3.0/) which permits unrestricted non-commercial use, distribution, and reproduction in any medium, provided the original work is properly cited. 